\title{
O ENSINO DE PORTUGUÊS COMO LÍNGUA ESTRANGEIRA: REFLEXÕES A PARTIR DA PRODUÇÃO ESCRITA DE ALUNOS CHINESES
}

\author{
LA ENSEÑAZA DEL PORTUGUÉS COMO LENGUA EXTRANJERA: REFLEXIONES \\ DESDE LA PRODUCCIÓN ESCRITA DE ALUMNOS CHINOS
}

\author{
TEACHING PORTUGUESE AS A FOREIGN LANGUAGE: REFLECTIONS FROM \\ THE WRITTEN PRODUCTION OF CHINESE STUDENTS
}

Tatiane Macedo $\operatorname{COSTA}^{1}$

RESUMO: Quando se aborda, particularmente, o ensino de Português para chineses, levantase uma discussão sobre as metodologias e abordagens utilizadas devido ao fato de o mandarim ser uma língua muito distinta do Português. Por um lado, defende-se ainda de maneira muito significativa que o ensino de português nesse contexto seja prioritariamente baseado em ensino de gramática. Por outro lado, tal foco destoa do padrão de domínio linguístico que se espera dos aprendizes de português como língua estrangeira nos exames do CAPLE (Portugal) e no CELPE-BRAS (Brasil). Diante disso, o objetivo do presente artigo é discutir essas questões a partir de exemplos de textos escritos por alunos chineses em uma universidade de Macau, China. A partir da análise das produções textuais, foi possível constatar que a prática de ensino voltada não somente à normatização gramatical permite que os alunos compreendam e produzam textos em que o desempenho comunicativo seja alcançado.

PALAVRAS-CHAVE: Português como língua estrangeira. Produção textual. Desempenho comunicativo.

RESUMEN: Cuando se aborda, particularmente, la enseñanza del idioma portugués a las personas chinas, se levanta una discusión sobre las metodologías y enfoques utilizados, dado que el mandarín es una lengua muy distinta del portugués. Por un lado, se sostiene aún de forma muy significativa que la enseñanza del portugués en ese contexto se debe basar prioritariamente en la enseñanza de la gramática. Por otro lado, tal enfoque desentona del estándar de dominio lingüístico que se espera de los aprendices de portugués como lengua extranjera en los exámenes del CAPLE (Portugal) y del CELPE-BRAS (Brasil). El objetivo del presente artículo es discutir esos temas a partir de ejemplos de textos escritos por alumnos chinos en una universidad de Macao, China. Desde el análisis de las producciones textuales, fue posible constatar que la práctica de la enseñanza orientada no solo a la normalización gramatical les permite a los alumnos comprender y producir textos en los que se alcance el desempeño comunicativo.

PALABRAS CLAVE: Portugués como lengua extranjera. Producción textual. Desempeño comunicativo.

${ }^{1}$ Universidade de Ciência e Tecnologia de Macau (MUST), Macau - China. Professora Assistente. ORCID: https://orcid.org/0000-0002-4891-1984.E-mail:tmacedocosta@must.edu.mo 
ABSTRACT: When it comes to teaching Portuguese specifically to Chinese students, a discussion is raised about the methodologies and approaches used since Mandarin is a very different language from Portuguese. On the one hand, it still has been strongly argued that the teaching of Portuguese in this context should be based on teaching grammar as a priority. On the other hand, such focus is not on agreement with the pattern of linguistic proficiency expected from learners of Portuguese as a foreign language in exams from CAPLE (Portugal) and in the CELPE-BRAS (Brazil) exam. Therefore, the aim of this article is to discuss these issues from examples of texts written by Chinese students at a university in Macau, China. From the analysis of textual productions, it was possible to verify that the teaching practice focused not only on grammatical standardization allows students to understand and produce texts in which communicative performance is achieved.

KEYWORDS: Portuguese as a foreign language. Text Production. Communicative performance.

\section{Introdução}

Nos últimos anos, a produção científica acerca do ensino de Português como Língua Estrangeira (PLE) tem ganhado destaque devido a um conjunto de especificid ad es que devem ser consideradas nesse processo (QIAORONG, 2008; BARBOSA, 2015; CHRISTIANO, 2017; SOUZA NETO, 2018).

É consensual o fato de que as metodologias e abordagens aplicadas no ensino de PLE não devem ser aquelas adotadas no ensino de português como língua materna.

Quando um professor nativo de PLE tenta utilizar os mesmos exercícios que teve enquanto estudava Português como Língua Materna na escola, vai provavelmente expor a seus alunos exercícios que são demasiadamente difíceis e que, na maioria dos casos, não são adaptados a quem aprende PLE (CHRISTIANO, 2017, p. 67).

Somado a isso, tem-se o problema muitas vezes da falta de material didático adequado. No contexto do ensino de Português aos alunos chineses, a questão da escassez de materiais didáticos tem sido amplamente discutida (ZHILIANG, 2019; YIXING, 2019; SHANPEI, 2019). Embora já se produza hoje na China materiais didáticos bilíngues voltados ao ensino de Português como língua estrangeira aos chineses, argumenta-se que os materiais existentes ainda não são suficientes.

Segundo Yixing (2019), “a elaboração de materiais didáticos serve para facilitar e melhorar o processo de ensino, sem dúvida nenhuma. Portanto, é tão importante quanto o método de ensino de uma língua estrangeira" (p. 155). Vê-se, portanto, que duas questões são 
costumeiramente abordadas: de quais recursos o professor lançará mão no ensino de PLE e como ensiná-lo.

Embora ambas as perguntas sejam relevantes e estejam intrinsecamente conectadas, o presente artigo tem como objetivo promover reflexões sobre a segunda pergunta. Para tanto, textos escritos por alunos da Universidade de Ciência e Tecnologia de Macau, China, serão considerados à luz dos princípios norteadores do exame de nível B2, Diploma Intermédio de Português Língua Estrangeira (DIPLE), aplicado pelo Centro de Avaliação e Certificação de Português Língua Estrangeira (CAPLE) da Universidade de Lisboa, bem como do exame CELPE-BRAS.

\section{Como ensinar Português como Língua Estrangeira na China}

O ensino de PLE no contexto chinês tem suscitado discussões sobre qual seria o seu método mais adequado devido às diferenças significativas entre o mandarim ${ }^{2}$ e o português, dentre elas a ausência de processos flexionais, preposições e determinantes (artigos) em mandarim (LOPES; YIXING, 2018). Tais distinções linguísticas têm servido de base, muitas vezes, para que se defenda um ensino de português baseado prioritariamente na gramática e na tradução.

Barbosa (2015), ao discutir sobre a sua experiência de ensino de PLE aos estudantes chineses, afirma que, dadas as distinções linguísticas, cognitivas e culturais, a possibilidade de os alunos chineses se ancorarem na língua materna como um elemento facilitador na aprendizagem do português é comprometida. Diante disso, a autora defende que a estratégia de estímulo ao conhecimento metalinguístico seja adotada.

Nesse sentido, a autora argumenta que o ensino deveria ser focado nos elementos e nas regras da língua em diferentes níveis: fonético-fonológico, morfológico e sintático. Além disso, sustenta que os níveis semântico e pragmático também devem ser considerados.

Ainda segundo Barbosa (2015), os estudantes chineses já estão habituados a um ensino voltado à gramática, devido ao sistema de ensino comumente adotado na China. Assim, "o conhecimento explícito dos elementos, do funcionamento e das regras da língua fornece a segurança de que necessitam para se aventurarem no campo da comunicação, da interação linguística” (BARBOSA, 2015, p. 121).

\footnotetext{
${ }^{2}$ Embora na China haja uma diversidade linguística muito grande com a existência de diferentes dialetos, neste texto, faz-se referência a mandarim, pois os alunos que produziram os textos que serviram de ba se à discussã o aqui apresentada são majoritariamente falantes de mandarim.
} 
Desse modo, a referida autora acredita que as dimensões referencial e pragmática serão mais facilmente alcançadas se os alunos tiverem um sólido conhecimento metalinguístico. Para Barbosa (2015, p. 122),

[...] é este conhecimento, por tudo o que do ponto de vista da aprendizagem e da relação emocional com o objeto de estudo engloba, que cria as condições para a exploração da vertente interacional ou comunic ativa da língua, sendo que é esta que realmente se visa alcançar no processo de ensino-aprendizagem de uma língua estrangeira.

Embora haja um forte argumento acerca da necessidade de aprimorar o conhecimento metalinguístico dos alunos como forma de sustentação para o desenvolvimento de outras habilidades, na prática, o que se verifica no contexto de ensino de PLE na China é ainda uma conduta voltada prioritariamente ao ensino de gramática.

De acordo com Shang, Teixeira e Silva (2019), apesar de haver um discurso corrente no qual muitos afirmam priorizar a comunicação no ensino de línguas, "o que se verifica, no entanto, é que as práticas continuam entendendo ensino de língua como um conjunto de atividades que privilegiam a gramática, o vocabulário e a tradução” (p. 243).

Em sua dissertação de mestrado sobre Aprender Português na China, Mai (2006) afirma que os estudantes chineses estudam português em um ambiente em que o uso efetivo da língua é bastante limitado. Sobre a metodologia, a autora diz que esta possui as características do Grammar-translation method ${ }^{3}(\mathrm{KONG}, 2011$, p. 76), o que, segundo ela, é eficaz porque os estudantes chineses possuem boa memória e preferem estudar materiais escritos a expressar-se oralmente, não sendo muito ativos nas aulas.

No entanto, ainda de acordo com Mai (2006), apesar de compreenderem o que os seus professores chineses falam em Português, cerca de 50\% dos alunos investigados em sua pesquisa $^{4}$ afirmaram sentir dificuldades em compreender o português falado por nativos.

Segundo Zhang (2019), no contexto chinês de ensino e aprendizagem de PLE, "as dificuldades dos aprendentes resultam não somente da fonética-fonologia, sintaxe e da semântica, como também da pragmática, que permitirá entender a intenção implícita do locutor" (p. 310).

\footnotetext{
3 "The grammar-translation method is a tra ditional method for foreign language teaching [...] in which the target language is translated into the mother tongue, that is, grammar teaching and translation exercises are mainly relied on to teach a foreign language. Its core lies in that when learning a foreign language, its grammatical rule system should be learned and memorized and used when translating literature works and sentences from the target language to the mother tongue" (KONG, 2011,p. 76).

${ }^{4}$ As conclusões da autora estão ba seadas em um questionário aplicado em sua pesquisa a os alunos do Curso de Licenciatura em Língua e Cultura Portuguesas da Universidade de Estudos Internaciona is de Xangai.
} 
Desse modo, verifica-se que o ensino de gramática é importante, mas não deve ser o único foco ao se ensinar uma nova língua, pois, se assim o for, acarretará dificuldades aos alunos no momento de exposição a contextos reais de uso da língua estrangeira. Sobre isso, Shang, Teixeira e Silva (2019) defendem que "a competência gramatical é necessária para que ocorra a interação, mas não é a única na gênese do processo de produção e compreensão linguística" (p. 249). Ainda segundo eles, "é a dimensão pragmática que orienta a produção/compreensão de sentidos e inclusive demarca a constituição da própria gramática" (p. 249-250).

Ao tratar do desafio de se ensinar português para falantes de outras línguas, Rosa (2012) salienta, a partir de pressupostos da Escola de Genebra, a importância das capacidades (i) de ação (condições de produção do gênero), (ii) discursivas (organização textual) e (iii) linguístico-discursivas. Sobre a última, a autora afirma que

[...] as capacidades linguístico-discursivas são aquelas que pos sibilitam ao usuário da língua reconhecer e utilizar os mecanismos de textualização (recursos coesivos, elos lexicais e estruturas gramaticais) com responsabilidade, compreendendo o valor que as estruturas do código têm na produção de sentidos e na realização das práticas sociais mediadas pela língua (ROSA, 2012, p. 07).

Segundo Rosa (2012), “aprender uma nova língua é aprender a significar no novo idioma, agir por meio de um novo código, uma nova cultura, um novo modo de conceber o mundo" (p. 06). Dessa maneira, é inconcebível pensar o ensino de uma língua, qualquer que seja, sem levar em consideração que esse aprendizado deve englobar não apenas questões metalinguísticas, como também aspectos semânticos, pragmáticos, discursivos e culturais.

Diante disso, escolher adequadamente a metodologia ou a abordagem de ensino é fator primordial para que os alunos alcancem os seus objetivos principais, que, no caso da aprendizagem de uma língua estrangeira, relacionam-se com poder se comunicar e interagir na língua alvo. Portanto, a abordagem de ensino adotada deve promover um desempenho comunicativo ${ }^{5}$ satisfatório e não simplesmente a aprendizagem de regras.

Essa habilidade comunicativa também é o que normalmente se espera dos alunos em exames oficiais que avaliam o conhecimento da língua estrangeira. No caso da língua portuguesa, os exames existentes, apesar de possuírem peculiaridades, requerem que os alunos demonstrem competência e proficiência na língua.

${ }^{5}$ Neste texto, o termo desempenho está sendo entendido como parte da competência comunicativa. Para mais detalhes sobre o debate acerca das nomenclaturas, sugere-se a leitura de Silva (2004). 


\section{Exames de certificação em Língua Portuguesa}

Tanto Portugal como o Brasil possuem exames para certificação da proficiência em língua portuguesa. Referente a Portugal, há diferentes exames para cada nível e eles são realizados pelo Centro de Avaliação e Certificação de Português Língua Estrangeira (CAPLE) da Universidade de Lisboa. Neste artigo, será analisado apenas o exame de nível B2 (Diploma Intermédio de Português Língua Estrangeira, DIPLE), uma vez que esse é o nível que se espera dos alunos do terceiro ano de Estudos Portugueses que cederam os seus textos para a análise que será apresentada na próxima seção.

Segundo o CAPLE 6 , os seus exames avaliam as competências descritas no Quadro Europeu Comum de Referência para as Línguas (QECR), nos níveis que vão do A1 ao C2. Portanto, torna-se imprescindível compreender qual abordagem é adotada pelo QECR. Em seu documento oficial, estabelece-se que

[...] a abordagem [...] adoptada é, também de um modo muito geral, orientada para a acção, na medida em que considera antes de tudo o utilizador e o aprendente de uma língua como actores sociais, que têm que cumprir tarefas (que não estão apenas relacionadas com a língua) em circunstâncias e ambientes determinados, num domínio de actuação específico. Se os actos de fala se realizam nas atividades linguísticas, estas, por seu lado, inscrevem-se no interior de acções em contexto social, as quais lhes atribuem uma significação plena (CONSELHO DA EUROPA, 2001, p. 29).

A partir das orientações do QECR, o CAPLE apresenta descritores do que se espera dos utilizadores da língua em cada nível avaliado. Sobre o nível B2 (DIPLE) ${ }^{7}$ especificamente, espera-se que os utilizadores da língua exibam um grau de independência que lhes permitam interagir em variadas situações de comunicação. Além disso, a descrição desse nível prevê: (i) uso compreensão de expressões idiomáticas comuns; (ii) entendimento de informações factuais em textos orais ou escritos, de modo que o utilizador possa distinguir entre informações principais e secundárias; e (iii) capacidade de produzir diferentes tipos de textos.

Apesar de o descritor para esse nível considerar a possibilidade de ainda haver muitas dificuldades nos contextos em que o português é língua de trabalho e de comunicação, também prevê que o utilizador tenha desenvolvido recursos linguísticos-comunicativos (identificação e uso das principais estruturas léxico-sintáticas e sintático-semânticas da

${ }^{6}$ Informações retiradas do site oficial do CAPLE. Disponível em https://caple.letras.ulisboa.pt/pagina/1/caple Acesso em 30 de julho de 2021.

${ }^{7}$ Informações retiradas do site oficial do CAPLE. Disponível em https://caple.letras.ulisboa.pt/exame/4/diple Acesso em 30 de julho de 2021. 
língua), de modo a ser capaz de usar a língua em situações menos previsíveis. Por fim, o utilizador deve saber reconhecer o contexto adequado para a escolha de um registro mais ou menos formal e ter consciência de convenções sociais.

Percebe-se, portanto, que, para se enquadrar no nível B2, um utilizador da língua portuguesa deve dominar competências diversas que vão desde conhecimentos mais formais da língua à compreensão de mecanismos de adequação sociocultural. Baseando-se nesses pressupostos, os candidatos ao exame B2 do CAPLE devem se submeter à avaliação das seguintes competências: compreensão da leitura, compreensão e produção escritas, compreensão do oral, produção e interação orais.

Sobre o DIPLE, Souza Neto (2018) afirma que, por avaliar separadamente a compreensão do oral, compreensão da leitura e produção e interação escritas, o exame voltase para uma noção de proficiência mais voltada para a estrutura linguística, com ênfase nas competências lexical e gramatical para a comunicação.

No que se refere ao Brasil, o exame realizado é o Certificado de Proficiência em Língua Portuguesa para Estrangeiros (Celpe-Bras). Nesse caso, os alunos submetem-se ao exame e, a partir do desempenho alcançado, são atribuídos os níveis distintos de proficiência. De acordo com o seu documento base, os candidatos são avaliados a partir de um único exame, porque acredita-se que "as situações de interação social não são classificadas em níveis: o que distingue os níveis de proficiência são os recursos mobilizados pelo participante nas situações de interação propostas" (BRASIL, 2020, p. 33).

Quanto à sua estrutura, o exame Celpe-Bras é formado por duas partes: uma escrita e uma oral. Na parte escrita, avalia-se de forma integrada a compreensão oral, imagética, leitura e produção escrita em língua portuguesa. Para tanto, o participante deve cumprir quatro tarefas distintas que abrangem não somente a compreensão como também a produção. As tarefas envolvem a compreensão oral e imagética (vídeo) somada a uma produção escrita, a compreensão oral (áudio) juntamente com outra produção escrita e mais duas atividades que abarcam a leitura (compreensão) e posterior produção escrita.

No exame, entende-se tarefa como uma oportunidade para que os candidatos possam “usar a língua em diversos contextos, desempenhando papéis com variados propósitos e distintos interlocutores, produzindo textos de uma série de gêneros discursivos, que circulam em diversos suportes" (BRASIL, 2020, p. 31).

No que concerne à oralidade, a parte oral do exame Celpe-Bras visa aferir o desempenho do utilizador da língua portuguesa na compreensão e produção orais. No exame, 
a oralidade é entendida como prática social de interação que se manifesta de formas variadas para fins comunicativos.

O que se pode observar, portanto, a partir da descrição dos exames apresentada acima é que, mesmo com especificidades próprias, tanto o exame de nível B2 (DIPLE) do CAPLE como o Celpe-Bras têm em seus descritores uma avaliação que leva em consideração a competência comunicativa. Cumpre ressaltar que 'competência comunicativa' não se limita à oralidade. Mesmo em tarefas escritas, os exames consideram as situações de comunicação nas quais, em maior ou menor grau, as condições de produção são explicitadas para que o utilizador se atente aos propósitos da tarefa solicitada.

\section{O trabalho com o texto na aula de PLE à luz dos Exames de Certificação}

Embora o objetivo primário que leve uma pessoa a aprender uma nova língua não seja, muitas vezes, submeter-se a um exame de certificação, tais exames devem ser considerados, principalmente, quando o seu método de avaliação visa aferir a competência comunicativa do utilizador da língua, uma vez que, em geral, alcançar a referida competência é a meta de quem se dispõe a aprender uma língua estrangeira.

No que se refere especificamente à escrita, é preciso considerar que a produção de textos deve ser uma das habilidades a ser trabalhada quando se fala em ensino de PLE. Para tanto, é preciso considerar a existência de gêneros textuais diversos e é importante oferecer ao aluno meios de reconhecê-los e produzi-los.

Segundo Abaurre; Abaurre (2007), os textos, embora diferentes entre si, possuem pontos em comum, pois podem se repetir no conteúdo, no tipo de linguagem ou até mesmo na estrutura. Quando possuem um conjunto de características semelhantes, seja na estrutura, conteúdo ou tipo de linguagem, configura-se o gênero textual. Para as autoras, o gênero textual pode ser definido como as diferentes maneiras de organizar as informações linguísticas, de acordo com a finalidade do texto, o papel dos interlocutores e a situação.

De acordo com Rosa (2012), quando se fala em aprendizado de línguas, é preciso que essa aprendizagem priorize práticas reais de uso da língua, ou seja, é preciso formar "usuários da língua que saibam realizar suas ações cotidianas e conquistar coisas e espaços por meio do domínio dos gêneros necessários à sua realidade" (p. 05).

Diante disso, toma-se como exemplo algumas propostas de atividade escrita apresentadas e discutidas em um grupo de estudos com alunos chineses do curso de Estudos Portugueses da Universidade de Ciência e Tecnologia de Macau, China. As atividades 
visavam promover oportunidades para que os alunos pudessem praticar a escrita a partir de tarefas variadas.

Como a maioria dos alunos tinha como objetivo posterior submeter-se ao exame DIPLE (B2) do CAPLE, as propostas tentaram seguir o padrão de tarefa costumeiramente exigido no exame de Produção e Interação Escritas. Conforme poderá ser observado, as tarefas 01 e 02 apresentadas a seguir buscavam obedecer a noção de gênero discursivo, em que se tem um gênero a ser escrito (carta - pessoal ou de candidatura), interlocutores definidos e um propósito com a escrita.

\section{Tarefa 01}

Um(a) grande amigo(a) seu(sua) mudou-se para Portugal em 2019. Logo após a mudança, o mundo passou a enfrentar uma grande pandemia, fazendo com que o(a) seu(sua) amigo(a) ficasse impossibilitado(a) de regressar à terra natal. Escreva uma carta pessoal para o(a) seu(sua) amigo(a) para compartilhar como está a sua vida e como está a situação em Macau. Além disso, você quer saber como está a vida dele(a) em Portugal, como está a sua situação com as aulas e como acontece o enfrentamento ao vírus em Portugal.

\section{Tarefa 02}

Você estava a navegar por um site de empregos na internet e, de repente, depara-se com uma vaga para o posto de tradutor chinês-português. Então, você resolve escrever uma carta de candidatura para o referido posto em uma grande empresa multinacional. Apresente-se, escreva sobre as suas qualidades, refira alguma atividade profissional que já tenha tido. Caso nunca tenha trabalhado na área, faça referência aos seus estudos nesse campo. Escreva a carta para o diretor de recursos humanos da empresa e seja persuasivo de tal modo que quem publicou o anúncio queira convidar você para uma entrevista (Adaptado de Pascoal; Oliveira 2012).

Anteriormente à produção dos textos, houve um momento prévio de explicação sobre quais seriam os objetivos da escrita e quais elementos eram necessários no cumprimento das tarefas. Foi promovida uma discussão em classe sobre os elementos que caracterizam o gênero carta, a interlocução (o próprio aluno e um amigo (tarefa 01) e o próprio aluno e o diretor de recursos humanos (tarefa 02)) e o propósito de escrita descrito em cada um dos 
enunciados. Por fim, os alunos foram solicitados que escrevessem os textos em casa, sob a orientação de que não fizessem uso de dicionários ou de tradutores.

Em linhas gerais, os alunos cumpriram de maneira bastante satisfatória os elementos específicos pedidos. Em alguns textos, alguns elementos característicos do gênero carta não foram incluídos (como identificação do remetente e do destinatário com endereço [fictício]), mas em todas as cartas foram estabelecidas corretamente as relações de interlocução. Além disso, ainda que, por vezes, um dos itens solicitados fosse omitido, o propósito global da escrita foi cumprido, como se pode ver nos exemplos apresentados abaixo. Cumpre ressaltar que os nomes foram omitidos por questões de garantia do anonimato dos informantes.

\section{Figura 1 - Texto da tarefa 1}

Macau, 24 de março de 2021

\section{Cara XXX,}

Com estás? Há cerca de 2 anos que ficas em Portugal. Tenho muitas saudades tuas. A pandemia global interrompeu o ritmo de vida das muitas pessoas. Ouvi que as aulas na tua universidade ainda não eram presencial. Enquanto as aulas na minhã universidade são presencial a partir do semestre passado.

Contude, a pandemia na China já é controlada pelo governo. Não existe grande diferença entre os dias agora e o dias antes da pandemia. Só devemos usar máscara fora e não podemos viajar. No festival da primavera neste ano, alguns colegas voltaram para a terra natal. Eu voltei também para a cidade natal. Acho que os dia durante o festival de primavera foram muito bons, acompanhando os meus pais. Espero que a pandemia acabe em breve.

E como está a tua vida? A pandemia em Portugal já é controlada? Já moravas em Portugal por muito tempo e adoptaste a vida em Portugal? Quando é que podes voltar para a China? Espero pela tua resposta.

Bejinhos,

XXX

Fonte: Acervo da autora 
Figura 2 - Texto da tarefa 2

Macau, 6 de abril de 2021

Caro diretor de Recursos Humanos,

Estava a navegar pela sua página oficial na Internet para procurar emprego e, de repente, deparei-me com uma vaga para o posto de tradutor chinês-português. Este emprego interessa-me muito e é por isso que eu decidi escrever uma carta para você.

Sou uma estudante de terceiro ano da universidade. Apesar de a minha licenciatura não ser acabada, já ganhei o certificado de $\mathrm{C} 1$, o que faz com que eu tenha qualidade profissional. Além disso, ao longo do período de aprender português, sou uma estudante extraordinária com excelentes notas, nomeadamente, no curso de transição.

Eu nunca tenho trabalhado nesta área, mas acredito firmemente que tenho capacidade suficiente de resolver dificuldades no trabalho, porque estou sempre disposta a estudar ativamente. Adicionalmente, sou uma pessoa ativa e sociável, o que significa que eu possuo boa capacidade de comunicação. Parece-me que isso faz importante parte de transição. Como eu estudo e moro em Macau, o ambiente português é favorável à minha comprenção oral e com esta experiência, vou garantir a minha qualidade.

Se você tiver algum interesse em mim, pode ligar comigo. Aguardo ansiosamente a sua resposta.

Cumprimentos,

XXXX

Fonte: Acervo da autora

Tais propostas se aproximam daquelas adotadas pelo Celpe-Bras, embora nesse exame, "na parte escrita, são priorizadas tarefas que abordam relações de interlocução ligadas aos usos públicos da linguagem, em detrimento dos usos privados” (BRASIL, 2020, p. 30). Assim, ao invés de um e-mail ou carta pessoal a um amigo, poderia ser solicitada a escrita de uma carta do leitor, já que a última circula em um ambiente mais amplo, de uso público.

Além dos dois textos apresentados antes, também foi oferecida aos alunos uma proposta em que eles poderiam escolher entre escrever um texto de tipologia narrativa ou argumentativa, tal como acontece na tarefa 02 do exame de Produção e Interação Escritas do DIPLE (B2). Nesse caso, não há uma definição de gênero textual específico a ser solicitado. Atividades desse tipo não são encontradas no exame Celpe-Bras, pois, nesse exame, não há tarefas que focalizem tipologias, mas sim gêneros textuais.

\section{Tarefa 03}

Escreva um texto sobre $\underline{\mathbf{u m}}$ dos três tópicos apresentados seguidamente.

(Seu texto deve conter entre 160-180 palavras).

A | Há uma coisa de que nunca me vou esquecer... 
B | O mercado de trabalho está cada vez mais competitivo. Por isso, para sermos melhores e ganharmos mais, trabalhamos mais. Resultado: a vida profissional entra cada vez mais na vida pessoal, o que não é mau. Concorda ou, pelo contrário, acredita que a falta de separação entre a vida profissional e pessoal não é positiva.

$\mathrm{C} \mid \mathrm{Na}$ nossa sociedade, as novas tecnologias vieram substituir as pessoas e prejudicam as relações sociais. Apresente os seus argumentos contra ou a favor.

Para essa tarefa, adaptada de Pascoal e Oliveira (2012), os alunos receberam previamente breves explicações acerca da tipologia solicitada. No caso narrativo, o texto deveria descrever ações; já no argumentativo, deveria expor e defender um ponto de vista. A produção da tarefa 03 aconteceu em sala de aula e os alunos não utilizaram nenhum recurso como dicionário ou tradutores. Toma-se como exemplo a produção textual a seguir.

Figura 3 - Texto da tarefa 03 (opção B)

\begin{abstract}
Hoje em dia, o stress para os trabalhadores na sociedade está cada vez major. Há mais pessoas que querem ter uma vida mais rico ou oferecer uma vida melhor para a familia. Portanto, muita gente começa a trabalhar bastante duro a ganhar mais dinheiro. Algumas pessoas até trabalhar no tempe livre e deixar o "fronteira" entre a vida e o trabalho. No entanto, na minha opinião, isto não é uma ação positiva, poderá afetar a vida pessoal a uma maneira negativa.

Temos de admitir que podemos acabar mais tarefas se usamos o tempo da vida pessoal, e também podemos um emprego de que o chefe gosta. Mas acho que há muitas desvantagens. Primeiro, se use o tempo livre para trabalhar, não poderá ter o tempe para descansar. Então, o processo da sua trabalho pode ser cada vez mais inefciente e duro. Por outro lado, quando menos tempo tenha para a vida pessoal, menos tempo para ser acompanhado com a familia, a relação entre si e a familia provavelmente é afetado por isto.

Em conclusão, apesar de falta de seperação entre vida e trabalho pode ter alguns vantagens, é ainda mais negativa devido às influencias negativas possíveis que isto pode causar a sua vida pessoal.
\end{abstract}

Fonte: Acervo da autora

Caberia aqui fazer uma discussão acerca do enquadramento de uma tarefa como a 03 apresentada acima em comparação com o que os documentos oficiais sobre os exames de certificação dizem em relação à abordagem que adotam, ou seja, se - de fato - propõem tarefas através das quais as atividades linguísticas estão circunscritas em ações que se dão em um contexto social, em situações reais do dia a dia. 
No entanto, o que se objetivou, na verdade, com a exemplificação das tarefas e de algumas produções textuais dos alunos chineses que as cederam para análise, foi evidenciar que, caso seja feito um trabalho voltado às questões semântico-pragmáticas, os alunos conseguirão compreender o propósito da escrita, quem são os interlocutores e em qual gênero/ tipologia o seu texto deverá se enquadrar.

Isso não quer dizer que os textos sejam isentos de inadequações. A partir da leitura dos textos transcritos nas figuras 01, 02 e 03, é possível constatar desvios relativos à concordância de gênero nominal, concordância nominal de número, adequação de escolha lexical, flexão verbal, acentuação, pontuação e grafia. Diante disso, o professor de PLE deve realizar um trabalho que objetive sanar essas dificuldades. Contudo, se - ao ler textos como os exemplificados antes - o professor destacar somente as inadequações, o aluno julgará que não fez um bom trabalho e dificilmente adquirirá a confiança necessária para se tornar um utilizador independente da língua.

Por isso, o ensino de PLE deve envolver cada vez mais textos orais e/ou escritos em diferentes situações de comunicação, visto que os alunos precisam ser expostos a tarefas que simulem o uso real da língua e não somente àquelas que visem a repetição ou o preenchimento de lacunas para fixação de normas, por exemplo. Numa abordagem comunicativa de ensino, a gramática não deve ser esquecida e o desvio não deve ser ignorado, mas tais questões devem ser abordadas inseridas em um contexto em que os alunos sejam estimulados a usar a língua e, consequentemente, um conjunto variado de estruturas.

\section{Considerações finais}

A partir das reflexões propostas neste artigo, pode-se pontuar algumas questões referentes ao ensino de PLE. Primeiro, ensinar português como língua estrangeira envolve uma série de especificidades. Os alunos não dominam a língua e, por isso, as atividades propostas devem ser condizentes com o nível de conhecimento que possuem. Nesse contexto, é sempre importante que o professor tenha em mente que, quase sempre, o objetivo do seu aluno é tornar-se proficiente na língua estrangeira e não um especialista em analisá-la.

Diante disso, defende-se que é papel do professor de PLE não somente trabalhar questões relativas à gramática como comumente se defende. Se assim o for, os estudantes se sentirão cada vez mais despreparados quando se depararem com situações reais de uso da língua, em que são exigidas habilidades de adequação contextual e de compreensão de significados, por vezes, implícitos. 
Nos textos escritos pelos alunos chineses aqui apresentados, a despeito dos desvios, foi possível observar que houve compreensão da tarefa solicitada e um evidente cumprimento dos seus objetivos. Dessa maneira, espera-se que este texto contribua para que o ensino de PLE se volte cada vez mais para questões semântico-pragmáticas e discursivas, de modo que, ao serem solicitados que cumpram uma tarefa, os alunos possam identificar o seu propósito, quem são os interlocutores envolvidos, bem como o gênero na qual se enquadra.

Ao utilizar uma abordagem comunicativa que considere as práticas sociais de uso da língua, o professor de PLE estará oportunizando que os seus alunos alcancem, de fato, um desempenho comunicativo satisfatório que poderá ser evidenciado quando estiverem inseridos em uma situação autêntica de comunicação.

\section{REFERÊNCIAS}

ABAURRE, M. L. M.; ABAURRE, M. B. M. Produção de texto - interlocução e gêneros. 1. ed. São Paulo: Moderna, 2007.

BARBOSA, A. V. O papel da consciência (meta)linguística no ensino da língua portuguesa a alunos chineses. Letras \& Letras, Uberlândia, v. 31/2, p. 111-127, jul./dez. 2015. ISSN 1980-5799. DOI: 10.14393/LL62-v31n2a2015-6. Disponível em:

http://www.seer.ufu.br/index.php/letraseletras/article/view/31348/17643 Acesso em 20 jul. 2021.

BRASIL. Instituto Nacional de Estudos e Pesquisas Anísio Teixeira. Documento base do exame Celpe-Bras. Brasília, DF: INEP, 2020. 130 p. ISBN 978-65-5801-006-7. Disponível em:

https://download.inep.gov.br/publicacoes/institucionais/avaliacoes_e_exames_da_educacao_b asica/documento_base_do_exame_celpe_bras.pdf Acesso em 30 jul. 2021.

CHRISTIANO, C. C. A prática do Ensino do Português como Língua Estrangeira. Macau: Centro Pedagógico e Científico da Língua Portuguesa/ Instituto Politécnico de Macau, 2017. 294 p. ISBN: 978-99965-2-166-9.

CONSELHO DA EUROPA. Quadro Europeu comum de referência para as línguas: aprendizagem, ensino, avaliação. 1. ed. Lisboa: Edições Asa, 2001. Disponível em: http://www.dge.mec.pt/sites/default/files/Basico/Documentos/quadro_europeu_comum_refere ncia.pdf Acesso em 03, ago. 2021.

KONG, N. Establishing a comprehensive English teaching pattern combining the Communicative Teaching Method and the Grammar - Translation Method. English Language Teaching, v. 4, n. 1, mar. 2011. ISSN 1916-4742. e-ISSN 1916-4750. Disponível em: https://files.eric.ed.gov/fulltext/EJ1080388.pdf. Acesso em: 05 ago. 2021. 
LOPES, I. P.; YIXING, X. Áreas críticas do Português para chineses: gramática de desvios (análises e explicações). Macau, China: Instituto Politécnico de Macau, 2018. 351 p. ISBN 978-99965-2-199-7.

MAI, R. Aprender Português na China. O Curso de Licenciatura em Língua e Cultura Portuguesas da Universidade de Estudos Internacionais de Xangai: Estudo de Caso. 2006. 180 f. Dissertação (Mestrado em Estudos Portugueses) - Universidade de Aveiro, Aveiro, 2006.

PASCOAL, J. L.; OLIVEIRA, T. B. Exames de Português B2 - preparação e modelos. Editora Lidel. Lisboa: Porto, 2012.

QIAORONG, Y. De práticas sociais a gêneros do discurso: uma proposta para o ensino de português para falantes de outras línguas. 2008. 130 f. Dissertação (Mestrado em Linguística Aplicada) - Instituto de Letras. Universidade Federal do Rio Grande do Sul, Porto Alegre, 2008.

ROSA, A. A. C. O desafio de se ensinar Português para falantes de outras línguas: análise linguístico-discursiva de um livro didático para o ensino de PLE. Anais do SIELP, Uberlândia, v. 2, n. 1, 2012. ISSN 2237-8758. Disponível em: https://www.ileel.ufu.br/anaisd osielp/wp-content/uploads/2014/06/volume_2_artigo_016.pdf. Acesso em: 20 jun. 2021.

SHANG, X.; TEIXEIRA; SILVA, R. Imaginários sobre gramática no contexto universitário chinês de ensino de português como língua não materna. In: QIAORONG, Y.; ALBUQUERQUE, F. D. (org.). O ensino do português na China: parâmetros e perspectivas. Natal: EDUFRN, 2019.p. 239-308.

SILVA, V. L. T. Competência comunicativa em Língua Portuguesa (Que conceito é esse?). Soletras, Rio de Janeiro, v. 8, supl. 2004. Disponível em: https://www.epublicacoes.uerj.br/index.php/soletras/article/download/4498/3297 Acesso em 10 ago.2021.

SOUZA NETO, M. J. CELPE-BRAS e CAPLE: A proficiência em português como língua não materna em paralaxe. 2018. 123 f. Dissertação (Mestrado em Língua e Cultura) Programa de Pós-Graduação em Língua e Cultura, Instituto de Letras, Universidade Federal da Bahia, Salvador, 2018.

YIXING, X. Ensino de Português na Universidade de Estudos Internacionais de Xangai. In: QIAORONG, Y.; AlBUQUeRQUE, F. D. (org.). O Ensino de Português na China: parâmetros e perspectivas. Natal: EDUFRN, 2019. p. 141-161.

ZHANG, Y. Pragmática aplicada ao ensino de português como L2 na China. In: QIAORONG, Y.; ALBUQUERQUE, F. D. (org.). O Ensino de Português na China: parâmetros e perspectivas. Natal: EDUFRN, 2019. p. 309-328.

ZHILIANG, Y. Reforçar o intercâmbio e a cooperação para promover um melhor desenvolvimento do ensino da língua portuguesa na China. In: QIAORONG, Y.; ALBUQUERQUE, F. D. (org.). O Ensino de Português na China: parâmetros e perspectivas. Natal: EDUFRN, 2019. p. 87-96. 


\section{Como referenciar este artigo}

COSTA, T. M. O ensino de Português como Língua Estrangeira: reflexões a partir da produção escrita de alunos chineses. Rev. EntreLínguas, Araraquara, v.7, n. esp. 6, e021141, dez. 2021. e-ISSN: 2447-3529. DOI: https://doi.org/10.29051/el.v7iesp.6.15401

Submetido em: 22/08/2021

Revisões requeridas em: 06/10/2021

Aprovado em: 13/11/2021

Publicado em: 28/12/2021 